\title{
Knowledge creation and interaction: developing the concept of Virtual Utility
}

\author{
Anna Suorsa \\ University of Oulu \\ anna.suorsa@oulu.fi \\ https://orcid.org/0000-0003-1472-3675 \\ Laura Kohonen-Aho \\ University of Oulu \\ laura.kohonen-aho@oulu.fi \\ https://orcid.org/0000-0002-1834-7008
}

Keywords: knowledge management; knowledge creation; innovations; interaction

In the field of Knowledge Management, the role of knowledge creation has been highlighted as organizations strive to cope with the changing environment by developing new solutions (Cook \& Brown, 1999; Nonaka, 1994). In recent years, the dialogical nature of collaboration and knowledge creation has been acknowledged, and a few researchers have suggested that discussions in working context should be included in the examination of knowledge creation in organizations (Mengis \& Eppler, 2008; Tsoukas, 2009).

Tsoukas (2009, p. 942) has argued for dialogical understanding of knowledge creation: "... although dialogue has been suggested (or implied) by several organizational knowledge researchers to be an important mechanism through which conceptual change and, thus, new knowledge emerges, it has not been adequate$l y$ theorized. We do not know enough about how dialogue works to generate new organizational knowledge." Tsoukas (2009) presents a thorough theoretical description of the process of creating new knowledge. This presentation examines knowledge creating discussions by relating them to Tsoukas' (2009) Dialogical 
Model for Organizational Knowledge Creation in Direct Social Interaction. The aim is to explore, how this theoretically deep and coherent model functions as a basis for empirical research of interaction and to find ways to examine dialogues in the process of knowledge creation in different contexts.

\section{Methods and data}

In this study, knowledge-creating interaction is examined in the multidisciplinary research community BCDC Energy, which is a multiorganizational and multi-professional community including researchers from two universities and five different disciplines: Energy Economics, Computer Science Engineering, Meteorology, Information Systems Sciences, and Information and Communication Studies. In addition, there are two strategic partners: The Carbon Neutral Municipality Forum and Finnish Clean Energy Association, and an Advisory Board, consisting of members of 16 private firms. The aim of the BCDC Energy consortium is to develop a digital market place for clean energy trading in Finland.

This study investigates how the BCDC community together with its partners developed the concept of Virtual Utility in a workshop. The data consists of video material gathered from a one-day workshop, which consisted of: 1) presentations and short discussions of the topics related to Virtual Utility and its need in the energy markets, 2) workshop, where four groups were developing their own conception of Virtual Utility in discussions, and 3) a wrap-up-discussion, where the groups presented their ideas. The joint presentations and discussions were recorded with two video cameras to allow examination of interaction from different angles. Each of the group discussions were recorded separately. In addition, documents of the BCDC community are analyzed to understand the role of Virtual Utility in the BCDC community. The analysis of the video data is conducted by examining the interactive process first as a whole. Then, the selected sequences are analyzed in a detail by utilizing techniques from multimodal conversation analysis (Mondada, 2016; Stivers \& Sidnell, 2012; see also McKenzie, 2009).

\section{Results and discussion}

Thus far, Tsoukas' (2009) approach has been acknowledged as useful and insightful, but it has not been used to examine discussions on a large scale, not just as individual examples of interactive phenomena. This study suggests that the longer phases of discussions and other knowledge processes in organizations 
should be included in the analysis, to be able to understand the relevance of the discussions. In addition, the focus of the analysis should be both in the content of the discussion and in the multimodal features of the discussion.

The results of this study show, how discussions can be analyzed and examined as part of a knowledge creation process. In addition, we illustrate, how different ways and modes to interact affect the process of creating new knowledge in face-to-face discussions. In future, the phenomenon should be studied in different organizations and communities to investigate the differences and similarities of the interactional phenomena in different contexts.

\section{References}

Cook, S. D. N., \& Brown, J. S. (1999). Bridging epistemologies: The generative dance between organizational knowledge and organizational knowing. Organization Science, 1o(4), 381-40o. https://doi.org/10.1287/orsc.10.4.381

McKenzie, P. J. (2009). Informing choice: The organization of institutional interaction in clinical midwifery care. Library \& Information Science Research, 31(3), 163-173. https://doi.org/10. 1016/j.lisr.2009.03.006

Mengis, J., \& Eppler, M. J. (2008). Understanding and managing conversations from a knowledge perspective: An analysis of the roles and rules of face-to-face conversations in organizations. Organization Studies, 29(10), 1287-1313. https://doi.org/10.1177/0170840607086553

Mondada, L. (2016). Challenges of multimodality: Language and the body in social interaction. Journal of Sociolinguistics, 20. https://doi.org/10.1111/jos1.1_12177

Nonaka, I. (1994). A dynamic theory of organizational knowledge creation. Organization Science, 5(1), 14-37. https://doi.org/10.1287/orsc.5.1.14

Stivers, T., \& Sidnell, J. (2012). Introduction. In The handbook of conversation analysis (pp. 1-8). Wiley-Blackwell. https://doi.org/10.1002/9781118325001.ch1

Tsoukas, H. (2009). A dialogical approach to the creation of new knowledge in organizations. Organization Science, 20(6), 941-957. https://doi.org/10.1287/orsc.1090.0435 